\title{
$\mathrm{XML}$ 기반 국가연구개발보고서 콘텐츠 서비스의 프레임워크 설계 \\ 손호선 ${ }^{1}$, 이종연 ${ }^{2^{*}}$ \\ ${ }^{1}$ 충북대학교 컴퓨터공학과, ${ }^{2}$ 충북대학교 컴퓨터교육과
}

\section{A Service Framework for Supporting XML-based National Research and Development Report Contents}

\author{
Ho Sun Shon ${ }^{1}$ and Jong Yun Lee ${ }^{2^{*}}$ \\ ${ }^{1}$ Department of Computer Engineering, Chungbuk National University \\ ${ }^{2}$ Department of Computer Education, Chungbuk National University
}

\begin{abstract}
요 약 정부 각 부처 단위의 국가연구개발보고서 정보관리 체계는 산하 전문기관으로 하여금 구체적인 정보의 수집 및 데이터베이스 구축, 정보시스템 운영 등의 업무를 수행하도록 하는 시스템으로 현행 국가 차원의 연구개발보고서 분류체계는 미흡한 상태이다. 또한 정부 부처마다 상이한 전자원문서비스 형태로 제공되므로 표준화된 서비스가 요구 된다. 따라서 본 논문의 연구 목표와 세부연구 내용은 다음과 같다. 연구 목표는 국가 연구개발보고서 양식의 표준화 방안을 수립하고, 기존 국가 연구개발보고서의 서비스 형태에 대한 문제점을 분석하여 XML 기반 국가연구개발보고 서 서비스를 위한 프레임워크를 제시한다. 아울러 본 논문의 세부 연구내용은 다음과 같다. 첫째, 국가 연구개발보고 서 생산 기관 현황파악 및 주요 기관별 연구개발보고서 양식조사와 서비스 현황을 분석한다. 둘째, 국가 연구개발보 고서 관련 주요 해외 과학기술정보 서비스 체계 및 관련 데이터베이스 스키마 분석을 한다. 셋째, 국가연구개발보고 서 서비스 체계의 문제점 분석을 통한 XML 기반 국가연구개발보고서 서비스 프레임워크 제안과 데이터베이스 스키 마를 설계하고 마지막으로 보고서 포털 서비스 방안을 제시하였다. 끝으로 본 논문의 학술적 기여도는 국가차원의 연 구개발보고서의 종합정보관리체계 구축을 통해 과학기술정보의 효율적인 관리 및 수요자 중심의 통합정보시스템 개 발을 통해 국가 연구개발 관련 정보와 자원을 공동 활용함으로써 연구개발의 투자 효율성을 높일 수 있다.
\end{abstract}

\begin{abstract}
The information management system for the national R\&D reports on the level of each government department have been operated in order to have special affiliated organizations collect detailed information, construct databases for R\&D reports, and operate their information system; thus, the current classification system for the $R \& D$ reports on the governmental level is insufficient. Also, each department requires to prepare a standardized electronic original text service system since mutually different electronic original text services have been provided. therefore, this paper sets up the following research goals and detailed research contents. The goals of this study are to establish methods to standardize the forms of national R\&D reports and suggest the framework for XML-based national R\&D reports services by analyzing the problems in the forms of previous national R\&D reports services. As detailed research contents, first, Identify the current R\&D electronic original reports services by each government department. Second, this paper analyzed primary overseas science technology information service systems related with national research and development reports and related database schemata. this paper proposed the XML-based national R\&D reports service framework through analyzing the problems in the framework of the existing national R\&D reports service system and also established and suggested the methods to provide database schema design and report portal services. Lastly, it is expected that this paper will have academic contribution to enhancing R\&D investment efficiency by utilizing collaboratively the information and resources related with national R\&D through establishing the general information management system for national-dimension R\&D reports and also managing science technology information efficiently and developing a user-centered integrated information system.
\end{abstract}

Key Words : National R\&D, Report of Electronic Original, E-R Schema Design, Database, XML

본 논문은 2010년도 한국과학기술정보연구원의 기관고유사업으로 수행하는 연구사업의 위탁연구과제(K-10-ID-11-02P-10)로 수행되었음.

"교신저자 : 이종연(jongyun@chungbuk.ac.kr)

접수일 10년 11 월 18 일 수정일 10년 12 월 15 일

게재확정일 11년 01월 13 일 


\section{1. 서론}

현대 사회는 과학기술 지식과 정보의 효과적인 창출, 확산 및 활용이 과학기술 경쟁력의 필수 요건으로 대두 되고 있다.

연구개발 성과정보서비스란 “국가연구개발사업의 투 자 효율성 제고 및 성과중심의 연구개발 체제 정착을 위 하여 연구성과를 종합하고, 효율적으로 제공하여 수요자 (정부부처, 연구자, 일반이용자)가 편리하게 활용할 수 있 는 체제를 지원하는 것이다"[1]. 연구개발 성과정보서비 스 구축 대상기관 중 대체적으로 교육과학기술부와 지식 경제부의 산하기관이 가장 많으며, 국가 연구개발보고서 도 활발히 작성되고 있다[1,12-14,17]. 그러나 지식경제부 산하 연구기관은 가장 많으나 실제 원문서비스가 되지 않는 곳이 많으며, 농촌진흥청과 농림수산식품부는 최종 보고서 검색은 가능하나 실제 원문 서비스는 잘 되지 않 고 있다[15]. 문화관광부 소속 한국문화콘텐츠진흥원은 비교적 서비스가 잘되고 있다[22]. 또한 중기청 산하인 한국산업기술평가관리원은 단순 게시판을 제공하지만 원 문은 PDF 파일로 제공되고 있다[23]. 방위사업청[24], 그 외, 식품안전관리청[25], 보건가족복지부[26]는 주로 임 직원만 이용 가능하여 국가 연구보고서 서비스가 미흡함 을 알 수 있다. 또한 특수한 목적으로 설립된 “-사업단”의 경우 대부분 연구결과 성과물의 웹서비스 제공이 이뤄지 지 않음을 알 수 있다. 이러한 지원 기관들도 기관마다 PDF, XML, HWP, HTML, PPT 등의 다양한 원문 형태가 지원되므로 표준화된 파일 서비스가 요구되며, 지원 기관 마다 내부인만 접속 가능한 경우와 로그인 후에 사용 가 능한 경우 등의 표준화도 요구되고 있는 상태이다. 이러 한 조사 분석 결과를 바탕으로 문제점을 파악하고, 정부 정보관리 유통체계는 산하 전문기관으로 하여금 구체적 인 정보의 수집 및 데이터베이스 구축, 정보시스템 운영 등의 업무를 수행하도록 하는 체제로 운영되어야 할 것 이다. 즉 국가 연구보고서의 정보관리 유통시스템의 표준 화 방안을 수립하여 국가 차원의 전문연구기관이나 성과 물관리전담기관에서 국가연구보고서를 중복없이 한번 구 축하고 사용자에게 항상 동일 수준의 연구보고서 서비스 제공이 되어야 할 것이다. 국가과학기술정보유통 전담기 관인 한국과학기술정보연구원으로부터 효율적인 자료 수 집과 국가차원에서 공동 활용함으로써 연구개발투자 효 율성을 극대화하고, 국가차원의 종합정보관리체계 구축 을 통해 국가 연구개발사업의 종합관리 지원이 이루어질 수 있도록 되어야 한다.

따라서 본 논문에서는 국가 연구보고서의 표준화된 서 비스를 위해 기존 연구보고서 서비스의 문제점을 분석하
고, 국가연구보고서를 위한 표준화된 양식안을 제안하고 이를 활용하여 XML 기반 콘텐츠 서비스 프레임워크 제 시를 목적으로 한다. 아울러 세부적인 연구내용은 다음과 같다. 첫째, 정부부처별 국가연구보고서 생산기관 현황 파악 및 정부부처별 주요 연구기관별 국가연구보고서 양 식 조사와 서비스 현황 분석을 하였다. 둘째, 국가연구보 고서 관련 주요 해외 과학기술정보인 Pubmed, PMC, 미 국 NTIS 서비스 체계 분석 및 관련 데이터베이스 스키마 분석을 하고, 셋째, 국가연구보고서 양식의 표준화 방안 및 작성지침을 제안하였다. 넷째, 기존 국가연구개발보고 서 서비스 체계의 프레임워크의 문제점 분석을 통해 XML 기반 국가연구개발보고서 서비스 프레임워크의 제 안하고, Public access를 위한 XML 기반 국가연구개발보 고서 웹서비스를 위한 데이터베이스 스키마 설계 그리고 Public access를 위한 XML 기반 국가연구개발보고서 웹 서비스 프레임워크 구현하였다. 끝으로 본 논문의 기대효 과는 국가차원의 연구개발보고서 종합정보관리체계 구축 을 통해 과학기술정보의 효율적인 관리 및 공동 활용이 기대되며, 수요자 중심의 통합정보시스템 개발을 통해 국 가연구개발 관련 정보와 자원을 공동 활용함으로써 연구 개발투자 효율성 높일 수 있다.

\section{2. 관련 연구}

국외에서 이미 사용되고 있는 XML 기반 의학 분야의 논문 서비스 형태인 Pubmed와 PMC (PubMed Central) 그리고 미국 상무성 산하 기관인 NTIS(National Technical Information Service)에 대한 원문서비스 이용 형태와 구조를 살펴본다.

\subsection{Pubmed 서비스}

의학분야의 서지 데이터베이스이며 pubmed에서는 의 학, 생활과학, 온라인 책 등에서 제공하는 4600 여 종의 생명과학 및 의학분야 저널에 수록된 약 190 만개 이상 의 논문에 관한 서지사항 및 초록이 제공되고 있으며, 링 킹(SFX) 서비스를 통하여 저널의 원문 데이터베이스로 연결 되거나, pubmed에서 검색한 자료를 마지막 노드로 반입하여 활용할 수 있다[3]. pubmed의 검색엔진은 entrez로 불리며, 주소창에 pubmed라고 입력하거나 http://www.ncbi.nlm.nih.gov/entrez/ 로 들어가서 이 entrez 를 사용해 볼 수 있다. 그림 1은 pubmed 데이터베이스 스 키마의 일부를 개체-관계 다이어그램을 간략히 표현하였 다. 의료분야의 데이터를 수집 관리하기 위하여 그림 1 같 
이 데이터베이스 테이블을 날자, 저널 이름, 논문 제목, $\mathrm{ISBN}$, 저자, 초록 등 12 개로 구성 되었다.

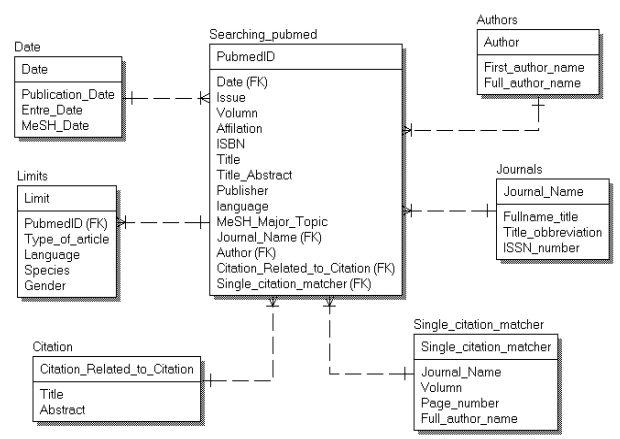

[그림 1] pubmed 데이터베이스 스키마의 개체관계 다이어그램

\subsection{PMC}

PMC(Pubmed Central)는 자유롭게 웹에서 의학 논문 을 누구나 볼 수 있게 수집하여 제공하는 곳으로 미국국 립의학도서관에서 2001년부터 작업을 시작하였다. PubMed보다 학술지 총수는 적지만 논문을 무료로 제공 받을 수 있다. 생명과학과 의학에 관계하는 사람들이 주 로 이용하며 학술지 논문의 전체 원문에 접근할 수 있도 록 XML을 이용하여 구현하였다. $\mathrm{PMC}$ 는 미국국립의학 도서관의 정보 기술을 활용하여 다양한 정보 검색서비스 를 제공하고 있다. $\mathrm{PMC} \mathrm{XML}$ 은 PubMed에서 자료를 $\mathrm{XML}$ 로 받아서 입력하는 것과 같이 논문 한편 한편을 모 두 XML로 처리하는 것이다. HTML은 대게 외형만 지정 하는 것이지만, XML에서는 내용이 어떤 속성을 지니고 있는지를 같이 표기한다. 예를 들어 제목, 저자, 및 소속 등이 어떤 내용이 지니고 있는지 속성을 표기한다[4].

\section{3 미국 NTIS 서비스}

NTIS(National Technical Information Service)는 미국 상무성 산하 기관으로 연방정부 용역으로 수행된 각종 연구개발 보고서와 해외 기술보고서를 수집 정리하여 데 이터베이스화 한 후 국내외로 공급하는 세계 최대의 정 보서비스 기관이다[2]. 정보의 수집 요약, 색인, 자료보관, 재생산 및 유통에 관한 모든 비용은 자체서비스 수입으 로 운영되고 있다. NTIS는 미국 정부와 외국 정부기관에 서 지원하여 발행한 비즈니스, 과학 기술, 공학 등 다양한 분야의 연구 개발 및 기술 보고서를 수집하여 유통한다. 정보는 인쇄물, CD-ROM, Disk, Online, Microfiche 등 다 양한 형태로 제공되며 현재 약 3,000 만 정도의 자료를 보
유하고 있다. NTIS의 주요업무는 정부 기관에서 산출되 는 정보를 통합적으로 제공할 수 있는 기반을 마련하고 있다. NTIS의 데이터베이스는 1964년부터 현재까지 과 학, 기술, 공학, 경영정보 등의 요약정보를 수록한 데이터 베이스로서 보고서 NERAC, Engineering Information(EI), Cambridge Scientific Abstracts, DIALOG, Ovid Technologies, SilverPlatter Information, DataStar, EBSCO Publishing, STN International/Chemical Abstract Service 등의 상용시스템들을 통해 온라인으로 제공된다. 그림 2 는 미국 NTIS 데이터베이스 스키마의 일부분을 개체-관 계 다이어그램을 보이고 있다.

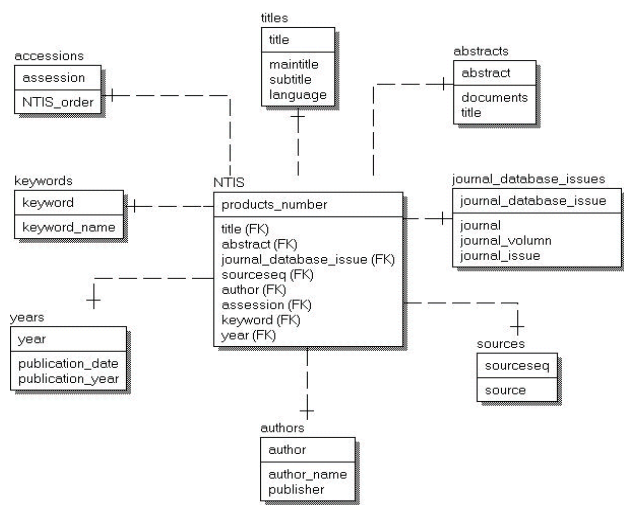

[그림 2] NTIS 데이터베이스 스키마의 개체-관계 다이어그램

\section{3. 국가연구보고서 양식의 표준화 방안}

현재 정부 부처 단위의 국가 연구개발사업의 연구 성 과물인 국가 연구개발보고서는 각 부처 간 서로 상이한 문서로 인해 사용자에게 동일한 수준의 서비스 제공이 어렵다. 정부 각 기관별 국가연구보고서의 원문서비스 현 황에서 보듯이 원문 서비스가 이뤄지고 있는 기관들도 기관마다 상이한 보고서 양식이 지원되므로 일정 수준의 <국가연구보고서 표준화>가 요구되고 있다. 우리는 이 연구에서 기존의 국가연구보고서 양식을 조사 분석하여 표 1 과 같은 개괄적인 국가연구보고서 양식의 표준안을 제안한다. 이 안은 기본적으로 꼭 들어가야 할 내용들이 지만 연구 목표나 주제에 따라 내용을 추가하여 사용할 수 있다.

[1] 연구개발과제의 개요: 작성 지침은 기존의 연구현 황을 요약하고, 기존 연구의 문제점을 기반으로 연 구개발의 목적과 필요성, 그리고 연구 목표와 연구 범위, 세부적인 연구내용을 구체적으로 기술한다. 
[2] 국내외 기술개발 현황: 국내외 관련 기술 현황, 연 구개발과정에 수집한 국내와 국외의 과학기술 정 보를 체계적으로 기술하고 연구결과가 국내외 기 술개발현황에서 차지하는 위치에 대해 기술한다.

[3] 국내외 기술개발 현황연구 개발 수행 내역 및 결 과: 작성 지침은 이론적, 실험적 접근 방법, 그리고 연구내용에는 연구개발 추진 일정과 추진 실적 기 재, 추진일정은 각 기관/기업별 역할 및 추진 내역 기재하고, 연구결과는 유형 및 무형 성과 전체를 기술한다. 즉 당초 기술개발 시작 시점의 조사와 변화된 것을 위주로 기술한다.

[4] 연구개발 목표 달성도 및 관련분야에의 기여도: 작 성 지침 방안은 연도별 연구목표 및 평가 착안점 에 입각한 연구개발 목표 달성도, 관련분야 기술발 전에의 기여도 기술 그리고 기술 개발 시 예상되는 기술적 - 경제적 파급 효과 및 목표대비 대외달성 도와 정량적 성과(논문게재, 특허출원, 기타)를 기 술한다.

[5] 연구개발결과의 활용계획: 작성 지침은 추가연구 의 필요성, 타 연구에의 활용계획, 실용화산업화 계획 및 추가연구, 타연구에 활용 계획 즉 기업화 추진 계획을 기술한다.

[6] 참고문헌: 작성 지침은 보고서 작성 시 인용된 모 든 참고문헌 열거한다.

[표 1] 국가연구보고서양식의 표준안

[1] 연구개발과제의 개요

목 차

$\checkmark$ 연구개발의 목적, 필요성 등을 기술

$\checkmark$ 연구 목표와 연구범위, 세부적인 연구내용

[2] 국내외 기술개발 현황

$\checkmark$ 국내외 관련 기술 현황

$\checkmark$ 연구개발과정에 수집한 국내와 국외의 기술개발 현황

$\checkmark$ 연구결과가 국내외 기술개발현황에서 차지하는 위치

[3] 연구개발 수행 내용 및 결과

$\checkmark$ 이론적, 실험적 접근 방법

$\checkmark$ 연구내용

$\checkmark$ 연구결과

[4] 연구개발 목표 달성도 및 관련분야에의 기여도

$\checkmark$ 연도별 연구목표 및 평가 착안점에 입각한 연구 개발 목표 달성도

$\checkmark$ 관련분야의 기술발전에의 기여도

$\checkmark$ 기술 개발 시 예상되는 기술적 - 경제적 파급 효과

[5] 연구개발결과의 활용계획

$\checkmark$ 추가연구의 필요성

$\checkmark$ 타 연구에의 활용계획, 실용화-산업화 계획

$\checkmark$ 타연구에 활용 계획

[6] 참고문헌

$\checkmark$ 보고서 작성 시 인용된 모든 참고문헌 열거

\section{Public Access를 위한 국가연구 보고서 서비스를 위한 프레임워크}

\section{1 기존 국가연구보고서의 문제점}

기존의 연구개발보고서 서비스 형태는 HTML에 기반 한 것으로 이에 따른 문제점을 이해하고, $\mathrm{XML}$ 기반으로 변환하면 어떤 면에서 장점을 얻을 수 있는지 알아본다. 기존에 사용된 국가 연구개발보고서를 위한 콘텐츠 프레 임워크를 살펴보면 그림 3과 같다. 그림 3 의 구조는 모든 연구개발 보고서를 데이터베이스에 저장하고, JSP와 JAVA를 연동하여 SELECT 문과 질의를 생성하고 데이터 베이스로부터 데이터를 받아 다시 JSP로 넘기고, HTML 으로 화면 출력할 수 있게 하였다. 데이터 입력은 결국 검색과 관련된 내용으로 사용자가 원하는 형태로 검색 할 수 있다. 그러나, 국가연구개발사업의 연구성과물인 국가 연구보고서를 중복없이 한번 구축하고 사용자에게 항상 동일 수준의 연구개발보고서 서비스 제공한다는 목 표에 부합하지 않는다. 즉, 각 부처 간 서로 상이한 문서 로 인해 사용자에게 동일한 수준의 서비스를 제공하기 어렵다. 따라서, 필요로 하는 과학기술정보를 쉽고 빠르 게 확인하여 연구소와 대학 간의 공동연구를 효과적으로 추진하기 위해서는 XML 기반의 국가 연구개발 보고서 를 위한 콘텐츠가 필요하다.

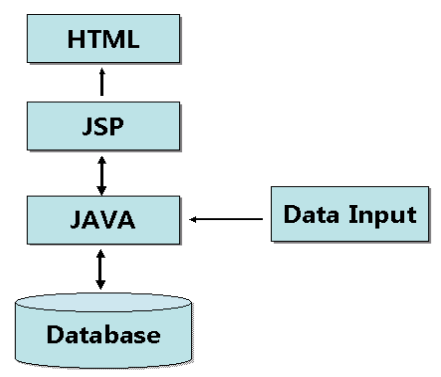

[그림 3] 기존연구보고서 시스템 구조

\section{2 국가연구보고서의 원문 서비스를 위한 문 서구조화의 필요성}

$\mathrm{XML}$ 은 웹상에서 구조화된 문서를 전송 가능하도록 설계된 마크업 언어이다. 고정된 요소(Tag, Element)만을 사용하는 HTML과는 달리 자유롭게 문서의 요소와 속성, 개체를 선언하여 자료를 구조적으로 표현할 수 있으며, 스타일시트(XSL)에 의해 다양한 형태의 문서를 나타낼 수 있다. XML이 언어(Languege)라고 불리지만 언어라기 보다 XML문법을 만족하는 언어를 만들기 위한 표준을 
정의한다. $\mathrm{XML}$ 을 사용하여 얻을 수 있는 장점을 살펴 보면 다음과 같다[5-7].

- HTML에서 처리할 수 없었던 복잡한 문서를 효과 적으로 전달할 수 있다.

- HTML에서의 태그를 XML에서는 Element라고 하 는데, XML 문서는 사용자가 엘리먼트를 직접 정 의할 수 있다.

- XML은 플랫폼과 프로그래밍 언어로부터 독립적 이므로 어떤 플랫폼에서 XML을 사용해도 제약받 지 않는다.

- 웹 기반의 애플리케이션들은 XML을 사용함으로 써 가능한 한 모든 정보를 클라이언트에 저장하여 웹서버의 부하를 줄일 수 있다.

- XML을 지원하는 소프트웨어들이 많이 등장하고 있으며 오라클, 사이베이스, MS-SQL서버 등을 비 롯한 데이터베이스MS와 각종 라이브러리, ERP, $\mathrm{SCM}$ 등의 Legacy system들도 $\mathrm{XML}$ 을 완벽히 지원 하겠다는 움직임을 보임으로써 대중화와 활성화될 수 있는 모든 기반을 갖추고 있다.

위와 같은 장점을 지닌 $\mathrm{XML}$ 을 기반으로 기존시스템 데이터와 데이터베이스에 저장된 연구 보고서를 사용자 에게 항상 동일 수준의 서비스를 제공하기 위해서 그림 4 와 같은 프레임워크를 설계하였다.

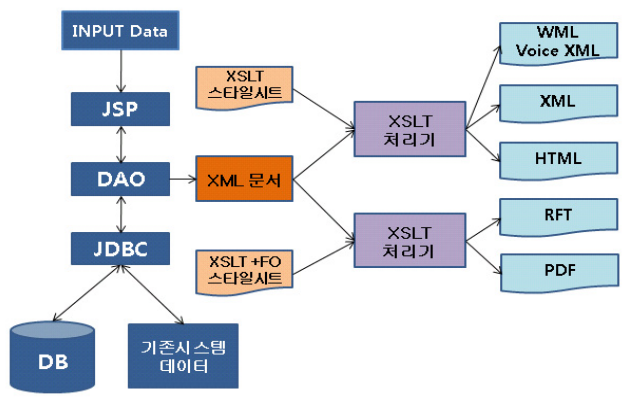

[그림 4] XML 기반의 국가연구보고서 서비스를 위 한 프레임워크

그림 4의 구조를 구체적으로 살펴보면, 기존 시스템의 데이터도 보장되면서 데이터베이스에 접속할 수 있도록 하는 자바 API인 JDBC(Java DataBase Connectivity)를 사용하고 응용프로그램 인터페이스인 DAO(Data Access Objects)는 프로그래머가 액세스 데이터베이스에 접속 요 청을 할 수 있도록 해준다. 이러한 $\mathrm{DAO}$ 는 서블릿의 사용 을 통해 웹페이지의 내용이나 모양을 제어하는 기술인 JSP(Java Sevelet Pages)와 연동을 통해 실제 웹서버에 의 해 실행될 자바프로그램을 호출한다. 웹 기반의 애플리케
이션들은 XML을 사용함으로써 가능한 한 모든 정보를 클라이언트에 저장하여 웹서버의 부하를 줄일 수 있다. $\mathrm{XSL}$ 은 $\mathrm{CSS}$ 과 더불어 XML 문서의 스타일을 정의하기 위한 언어로 XSLT-XML과 XSLT-FO 등의 두 가지 형태 로 구성된다[6].

제안된 시스템에서는 기존 시스템의 데이터 혹은 데이 터베이스의 데이터가 $\mathrm{JDBC}$ 와 $\mathrm{DAO}$ 와 연결되고, 일단 XML 문서로 변환된 다음에는 XSLT 를 이용해서 문서를 변환하게 된다.

XSLT는 XML문서를 다른 형태의 XML문서나 다른 형태의 문서(HTML, 텍스트 등)로 변환 할 수 있고, $\mathrm{XSL}-\mathrm{FO}$ 와 결합하는 경우 $\mathrm{PDF}$ 와 RDF 등의 문서로 변환 하는 작업을 수행할 수 있다. XML 문서를 다른 XML로 변환하기 위해서도 XSLT가 시용될 수 있다. 만약 A회사 와 $\mathrm{B}$ 회사가 거래를 할 필요가 있는데 $\mathrm{A}, \mathrm{B}$ 회사 모두 $\mathrm{XML}$ 을 사용하지만 문서 구조가 맞지 않는 문제가 발생 할 수 있다. 이러한 경우 A회사 문서를 XSLT를 이용하여 $\mathrm{B}$ 회사의 문서 구조에 맞게 변환할 수 있다. XML 문서 내용을 사람이 읽기 편한 형태로 변환해야 하는 경우도 있다. 예를 들어, 거래 실적이 XML문서로 되어 있는 경 우에 보고서를 제출한다거나, 혹은 프리젠테이션을 해야 하는 경우 XSLT와 XSLT-FO를 이용해서 RTF, PDF 또는 슬라이드 형태로 변환할 수 있다. XSLT는 XML 문서를 변환하기 위해서 변환 규칙들을 기술하게 되는데 이러한 규칙들은 XSLT 에서는 템플릿이라고 한다. XSLT 파일 은 템플릿들로 구성되어 있다. 템플릿 (template) 원소를 이용해서 기술하고, 템플릿 원소의 내용은 문서를 변환하 기 위한 명령어와 내용이 들어간다. 템플릿 원소는 규칙 이 적용될 XML 원소를 찾기 위해서, match 속성의 값으 로 XPath를 사용한다. XSLT 문서의 가장 상위 원소는 스 타일시트이고, 그 다음은 네임스페이스가 사용된다. 표 2 는 XSLT 문서의 전체적인 형태를 보여준다.

[표 2] XSLT 파일 형태

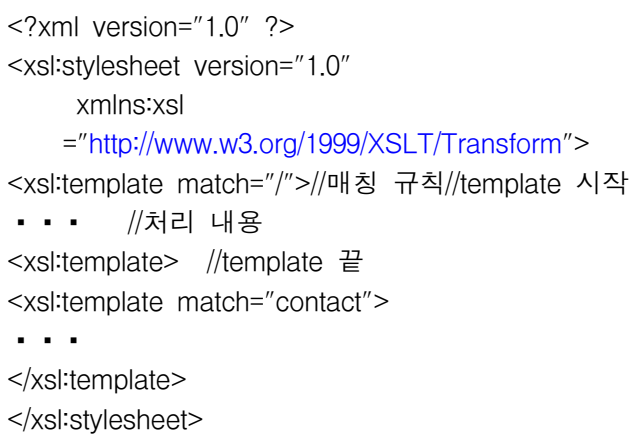




\subsection{XML 기반 연구보고서 콘텐츠를 위한 $\mathrm{XML}$ 스키마 구조}

웹서비스를 위한 표준 문서 데이터베이스 스키마는 2.2절에서 제시한 [표준화된 국가연구보고서의 양식]에 따라 웹서비스를 위한 데이터베이스 스키마를 생성하여 제시한다. 사용자는 여러 관계기관의 이질적인 데이터베 이스 소스로부터 데이터를 추출하여 원하는 형태로 제공 받기를 원하기 때문에 데이터에 대한 표준 스키마의 적 용을 요구한다. XML 기반 연구개발 보고서 서비스를 위 한 프레임워크 설계를 위해서는 먼저 데이터베이스 스키 마 즉, 논리적 스키마와 물리적 스키마가 생성 되어야 한 다. 그림 5의 웹서비스를 위한 국가연구개발보고서 저장 을 위한 개체-관계 다이어그램이다. 그림 6은 그림 5에 설계된 국가연구개발보고서에 대한 개체-관계 다이어그 램을 개념스키마로 설계한 것이다. 이러한 스키마의 설계 는 현재 상용 서비스되고 있는 pubmed, PMC, NTIS 데이 터베이스 개체-관계 다이어 그램을 기반으로 『국가연구 보고서 원문서비스』를 위한 각 엔티티와 엔티티를 구성 하는 속성들을 식별하여 데이터베이스 개체-관계를 정의 하였다. 그림 5 는 여덟 개의 엔티티와 그 엔티티를 구성 하는 속성들로 나타내었다. 각 엔티티의 구성은 다음과 같다.

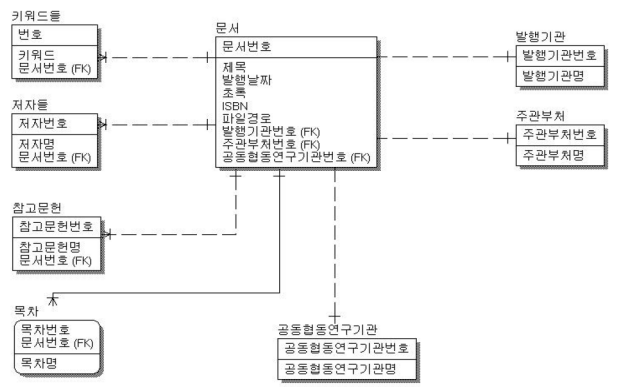

[그림 5] 웹서비스를 위한 국가연구보고서 데이터베이스 의 개체-관계 다이어그램

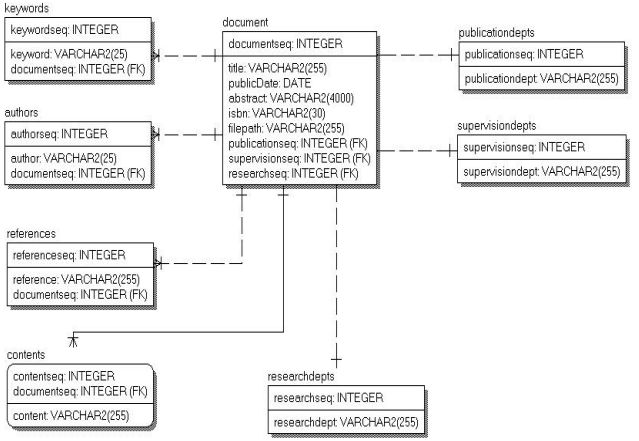

[그림 6] 웹서비스를 위한 국가연구 개발보고서 데이터베 이스 개념 스키마
[문서] 엔티티: 먼저 [문서] 엔티티는 문서번호가 기본키이며, 제목, 발행날자, 초록, ISBN, 파일경 로, 발행기관번호, 주관부처번호 그리고 공동협동 연구기관번호의 속성 값을 가지며, 이는 실제 각 엔티티를 설명하는 값들로 데이터베이스에 저장되 는 데이터의 주요 부분이다. 그 외 키워드, 저자, 참고문헌, 목차, 발행기관, 주관부처, 공동협동연구 기관 엔티티들은 [문서] 엔티티와 서로 관계가 성 립된다. 즉 [문서] 엔티티는 다른 엔티티들을 참조 한다. 특히 [목차] 부분의 내용은 앞 절에서 제시한 표준화한 양식을 통해 연구개발보고서 문서를 작 성할 수 있도록 한다.

[키워드] 엔티티: 키워드는 문서를 대표하는 단어 들로 구성되며, 테이블명은 키워드들이고, 기본키 는 번호이며 속성값으로 키워드와 문서번호를 쓸 수 있다.

[저자들] 엔티티: 저자들 엔티티는 저자번호가 기 본키이며, 저자명과 문서번호가 속성값을 나타낸 다.

[참고문헌] 엔티티: 참고문헌 엔티티는 참고문헌번 호가 기본키이며, 참고문헌명과 문서번호를 속성 값으로 표현할 수 있다.

[목차] 엔티티: 목차 엔티티는 목차번호와 문서번 호가 기본키이며, 목차 엔티티의 속성은 목차명이 다.

[발행기관] 엔티티: 발행기관 엔티티의 기본키는 발행기관번호이며, 속성은 발행기관명을 기진다.

- [주관부처] 엔티티: 주관부처엔티티는 기본키가 주 관부처번호이고, 속성값은 주관부처명이다.

[공동협동연구기관] 엔티티: 공동협동연구기관 엔 티티는 공동협동연구기관번호와 공동협동연구기 관명의 속성을 지니고 기본키는 공동협동연구기관 번호가 될 것이다.

[서비스 파일] 엔티티: 국가연구보고서 원문서비스 를 위해 출력 가능한 파일들의 형태, 즉 다음과 같 은 형식 pdf 의 파일로 출력할 수 있게 한다. 서비 스 파일의 엔티티의 속성들은 파일아이디 각 파일 경로 등이며, 파일아이디가 기본키에 해단하며, 데 이터베이스에 저장된 각 파일의 경로를 통해 원문 서비스를 할 수 있다.

\section{XML 기반 국가 연구개발보고서 콘텐츠 서비스}


기존 국가연구보고서의 원문서비스 문제점을 분석하 고, 그에 따른 대안으로 XML 기반으로 한 서비스 모형 을 구축하였다. XML은 자유롭게 문서의 속성, 개체를 선 언하여 자료를 구조적으로 표현 할 수 있으며, 스타일시 트(XSL)에 의해 다양한 형태의 문서를 나타낼 수 있다. 이 연구에서 제안하는 시스템 모형으로 설계된 프레임워 크에 기반하여 구축된 연구보고서 시스템은 다음과 같다. 먼저 그림 7은 국가연구보고서 원문 서비스를 위한 인터 페이스 화면이다.

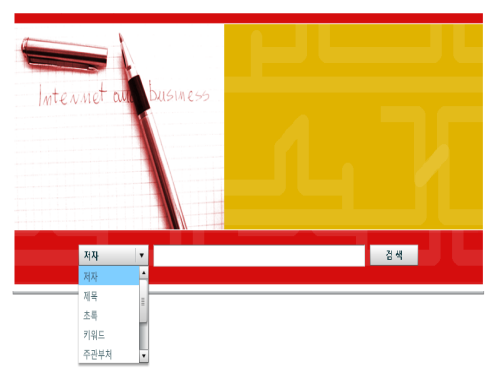

[그림 7] 국가연구보고서를 위한 인터페이스 화면

그림 7은 앞에서 제안한 데이터베이스 스키마와 개체관계를 이용하여 국가연구보고서 서비스를 JSP를 기반으 로 설계하여 만든 인터페이스이다. 다음은 제목을 입력 한 검색결과 출력 화면으로 나타낸 것으로 제목에 “스마 트 그리드” 란 단어를 입력함으로써 그림 8과 같이 출력 된다.

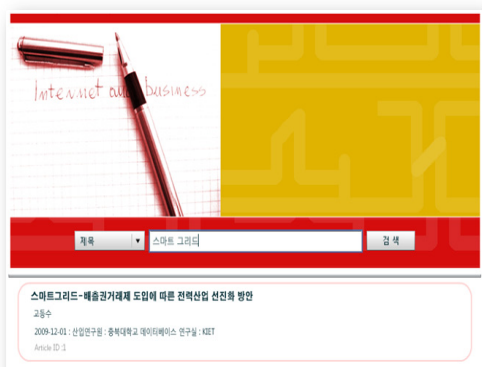

[그림 8] 제목을 이용한 출력

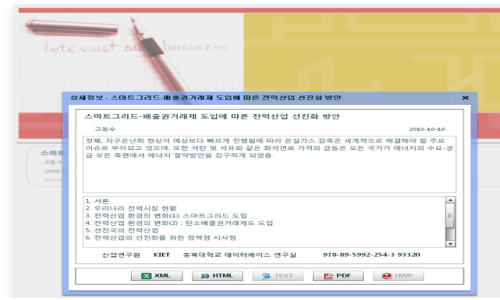

[그림 9] 보고서 제목 클릭시 상세 정보 출력
그림 9는 보고서 제목 클릭 시 해당 보고서의 상세정 보가 출력되는 것을 볼 수 있다. 화면 하단에는 JSP를 이 용하여 XML, HTML 그리고 경로 설정을 통해 원문파일 인 pdf 파일로 출력되게 구현 하였다.

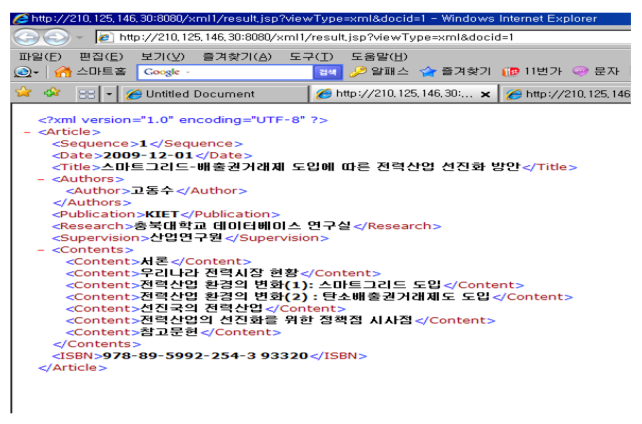

[그림 10] XML 문서의 서비스 형태

그림 10 은 XML 문서의 서비스 형태로 그림 9 의 XML 버튼 클릭 시 서비스 형태가 JSP로 구현된 XML 문서의 형태로 출력되는 것을 볼 수 있다. 다음 그림 11은 HTML 버튼 클릭 시 서비스 형태를 볼 수 있다.

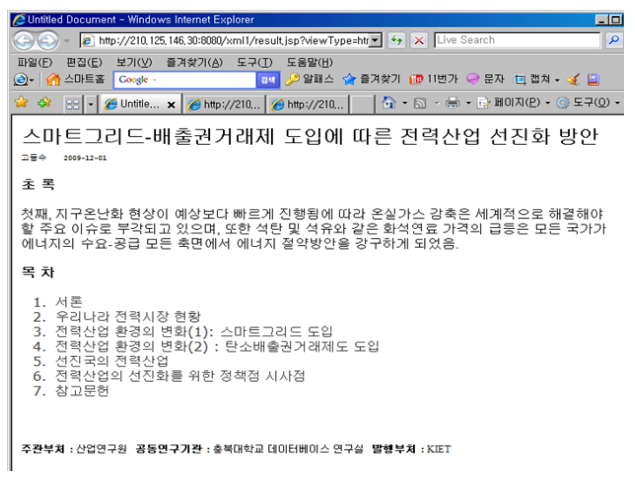

[그림 11] HTML 버튼 클릭 시 서비스 형태

그림 12는 PDF 파일의 서비스 형태로 경로설정을 통 해 출력됨을 알 수 있다. 따라서, 기존 데이터베이스와 새 로 생성된 데이터베이스에 접속할 수 있도록 하는 자바 API인 JDBC (Java DataBase Connectivity)를 사용하고 응용프로그램 인터페이스인 DAO (Data Access Objects) 는 프로그래머가 액세스 데이터베이스에 접속 요청을 할 수 있도록 해준다. 이러한 DAO는 서블릿의 사용을 통해 웹페이지의 내용이나 모양을 제어하는 기술인 JSP (Java Sevelet Pages)와 연동을 통해 실제 웹서버에 의해 실행될 자바프로그램을 호출한다. 


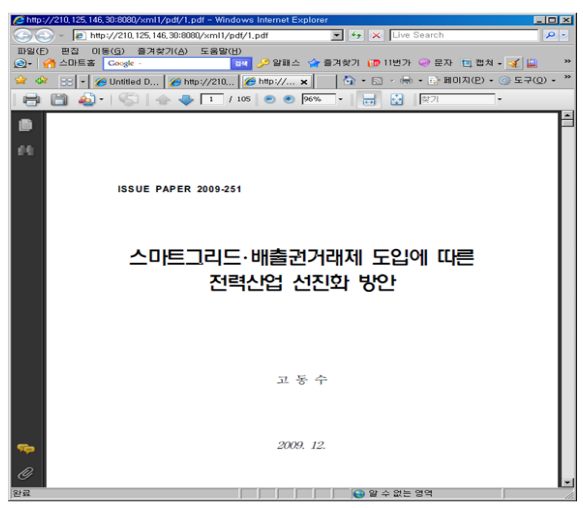

[그림 12] PDF 파일 형태의 서비스

이와 같이 국가 연구보고서의 서비스를 위해 JSP와 연 동하고 웹 애플리케이션을 위해서는 XML을 사용하여 좀 더 체계적인 국가 연구보고서의 원문 서비스가 원활 히 이루어 질 수 있을 것이다.

\section{5. 결론}

우리나라는 국가연구개발을 수행하고 있는 주요 부처 산하 연구관리 전문기관을 중심으로 다양한 사업들이 이 루어지고 있다. 그러나 국내 과학기술정보체계는 기관별 로 개별적, 독자적으로 추진되었기 때문에 체계화가 미흡 하고, 다양한 이용자들의 편이를 용이하게 제공하지 못했 다. 따라서 본 논문에서는 국가차원의 종합정보관리체계 구축을 위해 국가 연구개발사업의 종합조정을 지원하고 과학 기술정보의 효율적인 관리 및 공동 활용, 수요자 중 심의 통합정보시스템 개발에 있다. 즉 국가 연구개발관련 정보와 자원을 공동 활용함으로써 연구개발투자 효율성 을 제고시키는 것이다. 결국 이러한 것들을 수행하기 위 해 국가연구개발보고서에 대한 원문 서비스를 실시함으 로써 정부 각 부처나 연구기관 그리고 대학 등에서 서로 정보를 공유 할 수 있다. 또한 각 부처 간 및 연구기관마 다 서로 상이한 문서로 인해 사용자에게 동일한 수준의 서비스를 제공하기 어려웠으나, 국가연구개발보고서 문 서의 구조와 스타일을 표준화함으로써 데이터베이스에 저장된 데이터들을 사용자들은 항상 동일 수준의 서비스 로 제공 받을 수 있도록 한다. 그러므로 이 논문에서 제 안하는 것은 XML을 기반으로 한 국가연구개발보고서의 원문 서비스를 위한 프레임워크를 제시하고, 각기 다른 국가연구개발보고서의 양식 또한 표준화하여 그에 따른 데이터베이스 스키마를 생성하고 각 엔티티간의 관계를
설정한다. 따라서 XML 기반으로 작성된 제안 시스템은 각 기관에 산재되어 있는 각종 정보들을 통합하여 공동 활용할 수 있는 방향으로 추진 될 수 있을 것이다.

\section{참고문헌}

[1] http://www.kisti.re.kr, 2010

[2] http://www.ntis.gov, 2010

[3] http://www.ncbi.nlm.nih.gov/pubmed, 2010

[4] http://www.ncbi.nlm.nih.gov/pmc/, 2010

[5] http://www.w3.org/XML/, 2010

[6] 최종명, 유재우, 최재영, "자바 개발자를 위한 XML", 홍릉과학출판사, 2003.

[7] 홍송룡, "XML 원리와 응용”, 한빛미디어, 2003.

[8] 한건, 이상호, 안부영, “스키마 통합 기반 생명정보 검색시스템(BIRS)설계에 관한 연구”, 정보관리연구, vol.40, no.1, pp.217-234, 2009.

[9] 안부영, 송치평, “생명과학 문헌정보 네트워크 프로토 타입개발", 정보관리연구 vol.36, no.2, pp. 125-151, 2005.

[10] 임창주, 오세홍, “국가연구개발사업 종합관리시스템 의 성공적 구축방안", 한국정보관리학회지, vol.19, no.2, pp. 93-108, 2002.

[11] http://blogs.talis.com/nodalities/2009/06/britain2.php

[12] http://www.mest.go.kr/, 2010

[13] http://rnd.kosef.re.kr/index.jsp, 2010

[14] http://www.keei.re.kr, 2010

[15] http://www.rda.go.kr, 2010

[16] http://istk.re.kr, 2010

[17] http://www.mke.go.kr, 2010

[18] http://www.designdb.com/kidp/, 2010

[19] http://www.kitech.re.kr/

[20] http://www.keiti.re.kr/keiti?act=UI.IDX, 2010

[21] http://www.me.go.kr/, 2010

[22] http://www.kocca.kr/, 2010

[23] http://www.keit.re.kr/, 2010

[24] http://www.dapa.go.kr/, 2010

[25] http://rnd.kfda.go.kr/, 2010

[26] http://www.mw.go.kr/, 2010

[27] 윤성희, "질의어 의미정보와 사용자 피드백을 이용 한 웹 검색엔진의 성능향상", 한국산학기술학회논문 지, vol.8, no.2, pp. 280-285, 2007.

[28] 이봉근, 정재두, 류근호 "상황인지를 위한 지능형 $\mathrm{NPC}$ 프레임워크", 한국산학기술학회논문지, vol.10, no.9, pp.2361-2368, 2009. 


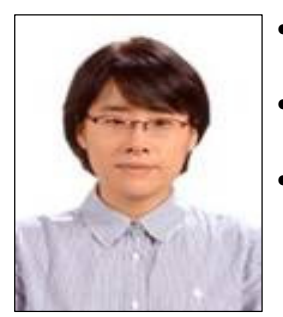

- 1992년 8월 : 성신여자대학교 대 학원 통계학과 (이학석사).

- 2010년 2월 : 충북대학교 대학원 전자계산학과 (공학박사).

- 2010년 9월 현재 : 충북대학 교 BIT사업단 연구원

<관심분야>

바이오 데이터마이닝, 데이터베이스, 의료통계분석, 패턴 인식.

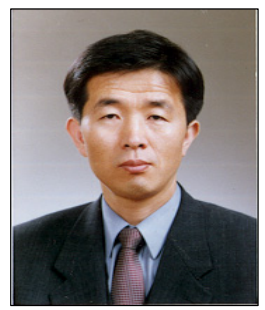

- 1985년 2월 : 충북대학교 전자계 산기공학과 (공학사).

- 1987년 2월 : 충북대학교 대학원 전자계산기공학과 (공학석사).

- 1999년 2월 : 충북대학교 대학원 전자계산학과(이학박사).

- 1990년 2월 1994년 10월 : 현대전자산업(주) 소프트웨어연 구소 주임연구원.

- 1994년 11월 1996년 5월 : 현대정보기술(주) CIM 사업부 책임연구원.

- 1999년 3월 2003년 2월 : 강원대학교 삼척캠퍼스 정보통신공학과 조교수.

- 2003년 3월 현재 : 충북대학교 컴퓨터교육과 교수.

<관심분야>

질의처리 및 최적화, 시공간 데이터베이스, GIS, 데이터 마이닝, 국제물류, u-Learning과 평가방법. 